\title{
Clinical outcomes of cervical spinal cord injuries without radiographic evidence of trauma
}

\author{
Yasuo Saruhashi, Sinsuke Hukuda, Akitomo Katsuura, Shuzo Asajima and Kikuo Omura \\ Department of Orthopaedic Surgery, Shiga University of Medical Science, Setatsukinowacho, Otsu, Shiga 520-21, \\ Japan
}

\begin{abstract}
We investigated 33 cervical spinal cord injury patients ( 25 males and eight females) without bony injury. Patients whose neurologic recovery had reached a plateau and who had evidence on imaging of persistent spinal cord compression were considered candidates for surgical decompression. When imaging did not show spinal cord compression or patients were maintaining a good neurologic recovery from the early days after injury, we pursued conservative treatment. Age at injury varied from 20 to 76 years (mean, 55.6). Average followup was 31 months. Twelve patients were treated conservatively (Group 1). Groups 2 and 3 had surgery. Group 2 (14 cases) had multi-level compression of spinal cord due to pre-existing cervical spine conditions such as ossification of posterior longitudinal ligament, cervical canal stenosis, and cervical spondylosis. Group 3 (7 cases) patients existed single-level compression of spinal cord by cervical disc herniations or spondylosis. We evaluated clinical results according to the Frankel classification, the American Spinal Injury Association (ASIA) scales and Japanese Orthopaedic Association (JOA) scores. Overall improvement of JOA and ASIA scores after treatment was $56.3 \pm 35.5 \%$ and $67.1 \pm 38.0 \%$, respectively. Patients in Group 1 showed very good recovery after conservative treatment, with improvement of JOA and ASIA scores being $70.4 \pm 40.2 \%$ and $77.4 \pm 34.2 \%$, respectively. The average interval between injury and operation was $4.3 \pm 4.4$ months. The improvement of the surgically treated patients (Groups 2 and 3) in JOA and ASIA score was $48.2 \pm 30.7 \%$ and $61.2 \pm 39.6 \%$ respectively. We obtained good neurological recovery after operation, with significantly more improvement in Group 3 than in Group 2. No significant neurologic recovery had occurred preoperatively in these groups. In such patients operative intervention is essential for neurologic recovery.
\end{abstract}

Keywords: cervical spinal cord injury; conservative and surgical treatment; prognosis

\section{Introduction}

The syndrome of spinal cord injury without radiographic abnormality (SCIWORA) is more common in children than in adults and represents a significant fraction of pediatric spinal cord injuries. ${ }^{1}$ SCIWORA can also occur in adults, but is much less frequent than the syndrome of acute spinal cord injury without radiographic evidence of trauma (SCIWORET). SCIWORET occurs in cervical spondylosis, spinal stenosis, ankylosing spondylitis, disc herniation, and other conditions. ${ }^{2}$ Cervical spondylosis is the most common associated condition in adults with SCIWORET. To varying degrees SCIWORET patients usually show central cord syndrome. Although a considerable number of patients with central cord syndrome make a substantial recovery without surgery, many have significant residual deficits, ${ }^{3}$ especially major impairments of the hands due to a combination of severe weakness and severe proprioceptive loss. All patients in

Correspondence: Y Saruhashi this study were asymptomatic before injury. At that point, we distinguish the acute aggravated cervical myelopathy from spinal cord injury. We believe patients with central cord injury whose neurologic recovery has reached a plateau and who have persistent deformity of the spinal cord on myelogram or magnetic resonance imaging (MRI) should have surgery. When these studies did not show spinal cord compression, or patients were maintaining good neurologic recovery from the early days after injury, we used conservative treatment including medication, traction and orthosis. In this study, we evaluated the clinical prognosis to assess our surgical criteria and our timing of surgery for SCIWORET patients.

\section{Materials and methods}

A total of 33 SCIWORET patients were investigated (25 males and eight females). All were asymptomatic before injury. Age at time of injury ranged from 20 to 76 years (mean, 55.6; standard deviation, 12.4). The 
average follow-up period was 31 months. The most frequent causes of injury were falls at ground level (16 cases, $48.5 \%$ ), followed by traffic accidents (11 cases, $33.3 \%$ ) and falls from a height (four cases, 12.1\%). The percentage of injuries thought to have occurred under the influence of alcohol was $15.2 \%$ (five cases). Physical findings and descriptions of accidents were analyzed to identify the mechanism of injury; 28 patients sustained extension injury, while the mechanism was undetermined in five patients. We found intramedullary lesions on 11 of 19 cases which we performed MRI examinations. On nine patients, the level of intra-medullary lesion extended from the most stenotic level.

We evaluated clinical results according to the Frankel classification, ${ }^{4}$ the motor scales of American Spinal Injury Association (ASIA), ${ }^{5}$ and the Japanese Orthopaedic Association (JOA) score $^{6}$ (range, 0-17; Table 1). The ASIA motor score is based on ten key muscles on each side, with a total maximum score of 100. Scores were measured when they first came to our attention and they were examined again at follow-up. Improvement was calculated as follows:

$$
\begin{aligned}
& \text { Improvement }(\%)= \\
& \frac{\text { posttreatment score }- \text { pretreatment score }}{\text { maximum normal score }- \text { pretreatment score }} \times 100
\end{aligned}
$$

All SCIWORET patients had central cervical spinal cord injury as described by Schneider et al. ${ }^{7}$

Table 1 Japanese Orthopaedic Association (JOA) score (range: $0-17$ points)

\footnotetext{
Motor function of upper extremity

4: Normal

3: Able to eat with chopsticks regularly, but slightly awkwardly

2: Able to eat with chopsticks, although awkwardly

1: Able to eat with spoon but not with chopsticks

0 : Unable to feed self with either chopsticks or a spoon

Motor function of lower extremity

4: Normal

3: Able to walk on a level surface and climb up stairs without a cane or support, but awkwardly

2: Able to walk on a level surface without assistive devices, but unable to climb up stairs without a cane or support

1: Needs a cane or support even for walking on a level surface

0 : Unable to walk

Sensory

Upper extremity 2: Normal

1: Slight sensory loss or numbness

0 : Definite sensory loss

Lower extremity As for upper extremity

Trunk

As for upper extremity

Bladder function

3: Normal, 2: Mild dysfunction, 1: Severe dysfunction,

0 : Complete retention of urine
}

By a system reported perviously ${ }^{8,9}$ they were classified into three types. In the first type, upper extremity impairment, deficits were confined to the upper extremities. The second, typical central cord syndrome, manifested Schneider-type impairment characterized by greater loss of motor power in the upper than lower extremities with varying degrees of sensory loss. The last type, incomplete transverse syndrome, had significant deficits in the lower extremities.

According to clinical course, type of lesion, and treatment, patients were divided into the three groups described below. Twelve patients were treated conservatively and 21 had operations. When radiological examination did not show compression of the spinal cord or patients were maintaining a good neurologic recovery from the early stage, we used conservative treatments including medication, traction and orthosis (Group 1). Head-halter traction (2-3 weeks) and cast application were among the conservative treatments used. Recently, we administered the patients methylpredonisolone sodium succinate (MPSS) following a protocol of the second National Acute Spinal Cord Injury Study (NASCIS 2). ${ }^{10,11}$ The total eight patients received MPSS following NASCIS 2 procedure, five of them in Group 1 and three of them in Groups 2 and 3.

When myelography or magnetic resonance imaging (MRI) showed evidence of cord compression and neurologic recovery had reached a plateau, we chose surgical treatment. Until the surgical treatment, we performed the same conservative treatment as Group 1. The surgical procedures used in this study were anterior inter-body fusion in 14 cases and laminoplasty in five cases. Two patients received both anterior interbody fusion and laminoplasty. Seven patients had onelevel anterior inter-body fusion, six had two-level fusion and three had three-level fusion. The surgical patients group were classified into two groups according to whether the principal lesion had characteristics indicating its presence on one level or multi levels. Patients in Group 2 (14 cases) had multi level lesions of the cervical spine predating injury such as ossification of posterior longitudinal ligament (OPLL, four cases), cervical canal stenosis (two cases) and cervical spondylosis (eight cases). The lesion treated operatively in Group 3 patients (seven cases) had single level anterior compression of spinal cord due to cervical disc herniation and/or cervical spondylosis. The operations showed the anterior spinal compression by osteophytes or disc herniations, while in the two cases we found the extruded disc heriations. In Groups 2 and 3 the duration between injury and operation was $4.3 \pm 4.4$ months. In Group 2, six had two-level anterior inter-body fusion, two had threelevel fusion and six had laminoplasty. Two patients received both anterior inter-body fusion and laminoplasty. In Group 3, seven had one-level anterior interbody fusion. No major surgery-related complications occurred in this series. 
Improvements in JOA and ASIA scores were calculated from assessments before treatment and at follow-up. Because the duration from the injury to the first examination at our clinic differed from a patient to a patient, the final score is important as well as the improvement. Variance is indicated in terms of standard deviation. Statistical differences were evaluated by the Wilcoxon signed rank test and considered significant at $P<0.05$.

\section{Results}

Overall $(n=33)$, significant neurological improvement occurred after treatment. The JOA score rose from $8.4 \pm 4.5$ to $13.0 \pm 4.4 \quad(P<0.0001)$, while the ASIA score changed from $77.5 \pm 26.2$ to $91.0 \pm 17.6$ $(P<0.001)$. Overall mean improvement by $\mathrm{JOA}$ and ASIA scores were $56.3 \pm 35.5 \%$ and $67.1 \pm 38.0 \%$, respectively. For the upper extremity impairment type (eight patients) improvement of JOA and ASIA scores was $75.4 \pm 37.3 \%$ and $100 \%$, respectively. For Schneider-type impairment (18 patients), improvement of JOA and ASIA score was $61.4 \pm 8.3 \%$ and $68.2 \pm 12.5 \%$, respectively. For the incomplete transverse impairment type (seven patients), improvement of JOA and ASIA scores was $21.4 \pm 7.3 \%$ and $27.5 \pm 12.2 \%$, respectively (Table 2 ).

Conservative-treatment patients (Group 1, $n=12$ ) included six patients with upper extremity impairment and six patients with Schneider-type impairment. Group 1 patients showed very rapid and significant clinical recovery. The six patients of Group 1 attained recovery of more than one grade by the Frankel classification within 3 weeks. During the whole examination period, $67 \%$ of Group 1 patients had one grade improvement, while $25 \%$ had two grades improvement (Table 4). Their scores increased from $8.8 \pm 5.3$ to $15.4 \pm 2.2(P<0.005)$ and from $76.5 \pm 28.8$ to $97.8 \pm 3.7 \quad(P<0.05)$ on JOA and ASIA scales, respectively, representing improvement by $70.4 \pm$ $40.2 \%$ and $77.4 \pm 34.2 \%$. In Group 1, six patients

Table 4 Summary prognosis in Group 1 patients $(n=12)$

\begin{tabular}{lcccc}
\hline AA & AB & AC & AD & AE \\
0 & 0 & 0 & 0 & 0 \\
BA & BB & BC & BD & BE \\
0 & 0 & 0 & 0 & 0 \\
CA & CB & CC & CD & CE \\
0 & 0 & 0 & 1 & 3 \\
DA & DB & DC & DD & DE \\
0 & 0 & 0 & 1 & 7 \\
EA & EB & EC & ED & EE \\
0 & 0 & 0 & 0 & 0 \\
\hline
\end{tabular}

In each square of the grid are two letters of the alphabet of Frankel classification, the first related to the neurological lesion on the first examination and the second to the neurological lesion on last follow-up

Table 2 Improvement in all patients, by impairment pattern

\begin{tabular}{|c|c|c|c|c|c|c|}
\hline & $\begin{array}{c}\text { JOA score on } \\
\text { the first } \\
\text { examination }\end{array}$ & $\begin{array}{l}\text { JOA score on } \\
\text { last follow-up }\end{array}$ & $\begin{array}{l}\text { Improvement } \\
\text { of JOA score }\end{array}$ & $\begin{array}{c}\text { ASIA score on } \\
\text { the first } \\
\text { examination }\end{array}$ & $\begin{array}{l}\text { ASIA score on } \\
\text { last follow-up }\end{array}$ & $\begin{array}{l}\text { Improvement } \\
\text { of ASIA score }\end{array}$ \\
\hline All patients $(n=33)$ & $8.5 \pm 4.5$ & $13.2 \pm 4.2$ & $57.7 \pm 34.5 \%$ & $77.7 \pm 26.2$ & $91.2 \pm 17.7$ & $64.7 \pm 39.4 \%$ \\
\hline $\begin{array}{l}\text { Upper extremity } \\
\text { impairment }(n=8)\end{array}$ & $13.1 \pm 2.7$ & $15.4 \pm 2.3$ & $77.2 \pm 31.5 \% \dagger$ & $92.7 \pm 4.3$ & $98.4 \pm 4.0$ & $89.1 \pm 26.6 \% \dagger$ \\
\hline $\begin{array}{l}\text { Schneider type } \\
\quad \text { impairment }(n=18)\end{array}$ & $7.2 \pm 3.8$ & $14.1 \pm 2.4$ & $65.8 \pm 27.8 \% \dagger$ & $79.5 \pm 25.6$ & $97.3 \pm 4.5$ & $70.7 \pm 35.9 \% \dagger$ \\
\hline $\begin{array}{l}\text { Incomplete transvere } \\
\text { syndrome }(n=7)\end{array}$ & $3.9 \pm 2.6$ & $6.5 \pm 3.7$ & $20.6 \pm 16.6 \%$ & $52.1 \pm 30.1$ & $67.1 \pm 26.9$ & $27.3 \pm 26.2 \%$ \\
\hline
\end{tabular}

Values are mean $\pm \mathrm{SD} . \dagger P<0.05$ (significant difference compared to incomplete transverse syndrome)

Table 3 Improvement and lesion causing spinal cord compression in surgical treatment Groups (2 and 3 )

\begin{tabular}{lcccccc}
\hline & $\begin{array}{c}\text { JOA score on } \\
\text { the first } \\
\text { examination }\end{array}$ & $\begin{array}{c}\text { JOA score on } \\
\text { last follow-up }\end{array}$ & $\begin{array}{c}\text { Improvement } \\
\text { of JOA score }\end{array}$ & $\begin{array}{c}\text { ASIA score on } \\
\text { the first } \\
\text { examination }\end{array}$ & $\begin{array}{c}\text { ASIA score on } \\
\text { last follow-up }\end{array}$ & $\begin{array}{c}\text { Improvement } \\
\text { of ASIA score }\end{array}$ \\
\hline $\begin{array}{l}\text { Groups 2 and 3 } \\
\quad(n=21)\end{array}$ & $8.2 \pm 4.1$ & $11.6 \pm 4.7$ & $48.2 \pm 30.7 \%$ & $78.0 \pm 25.4$ & $87.1 \pm 21.1$ & $61.2 \pm 39.6 \%$ \\
$\begin{array}{l}\text { Group 2 (multi-level } \\
\text { lesion, } n=14)\end{array}$ & $6.5 \pm 3.4$ & $9.5 \pm 4.4$ & $33.2 \pm 23.4 \% \dagger$ & $71.6 \pm 28.9$ & $82.0 \pm 24.0$ & $47.8 \pm 37.1 \%$ \\
$\begin{array}{l}\text { Group 3 (single-level } \\
\text { lesion, } n=7)\end{array}$ & $11.7 \pm 3.1$ & $15.7 \pm 1.1$ & $78.3 \pm 19.1 \% \dagger$ & $90.9 \pm 7.4$ & $97.3 \pm 7.2$ & $88.2 \pm 31.2 \%$ \\
\hline
\end{tabular}

Values are mean $\pm \mathrm{SD} . \dagger P<0.05$ (significant difference between Group 2 and 3 in JOA score) 
a

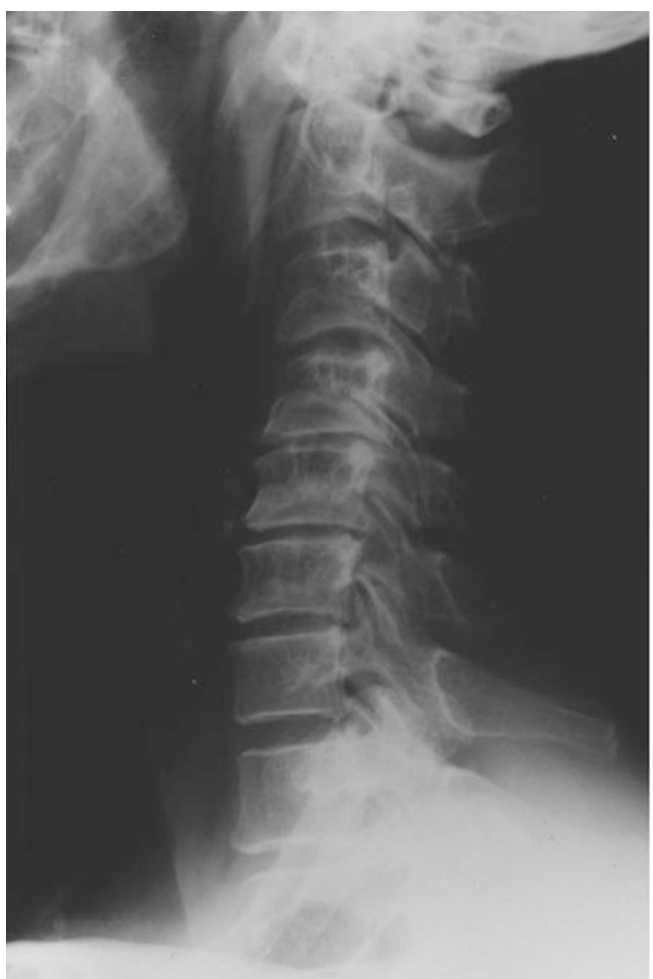

c

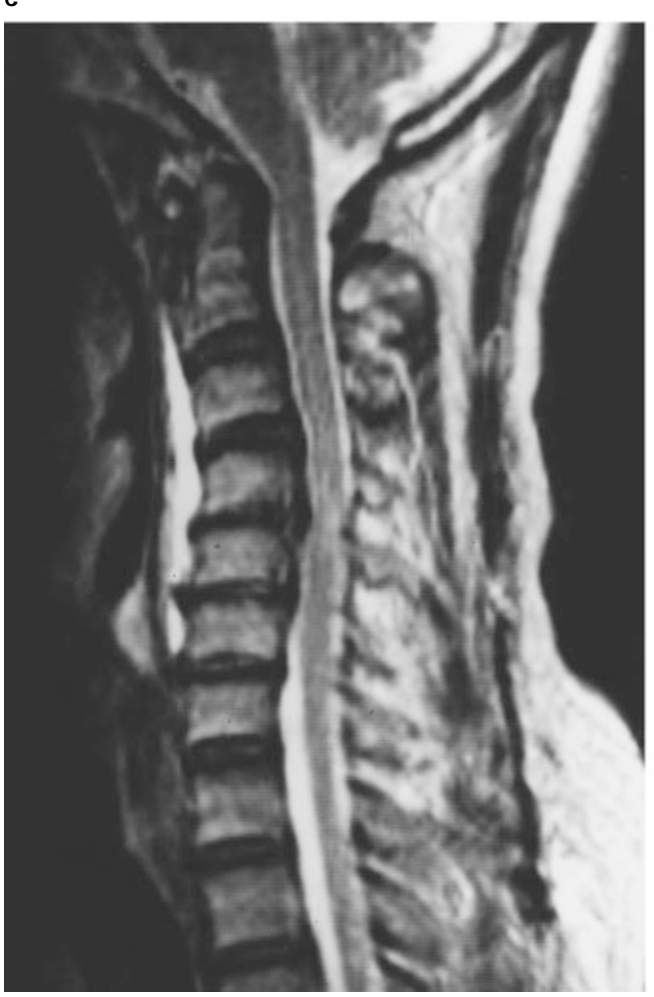

b

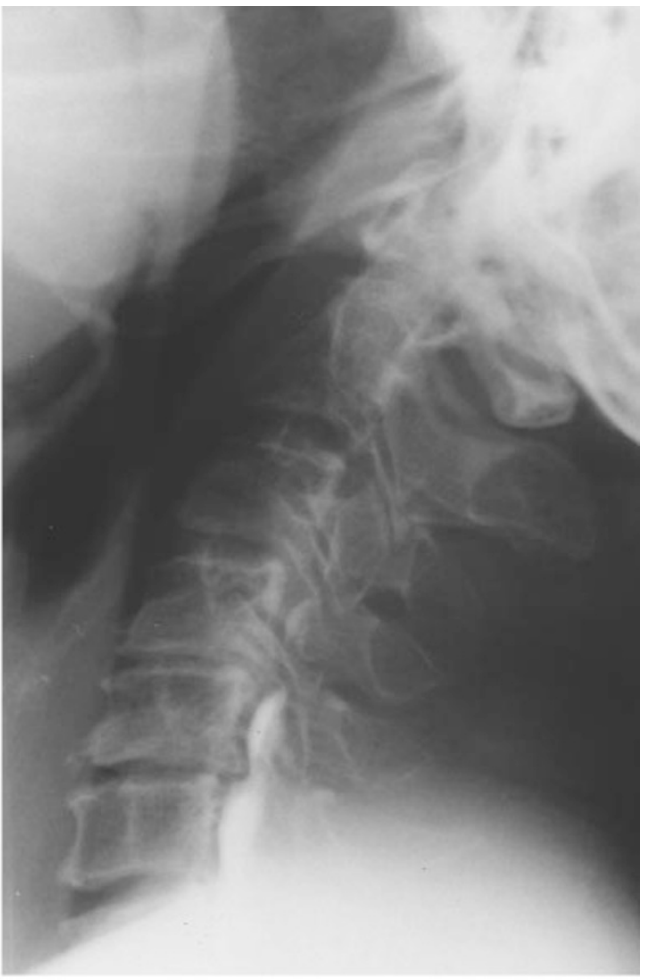

d

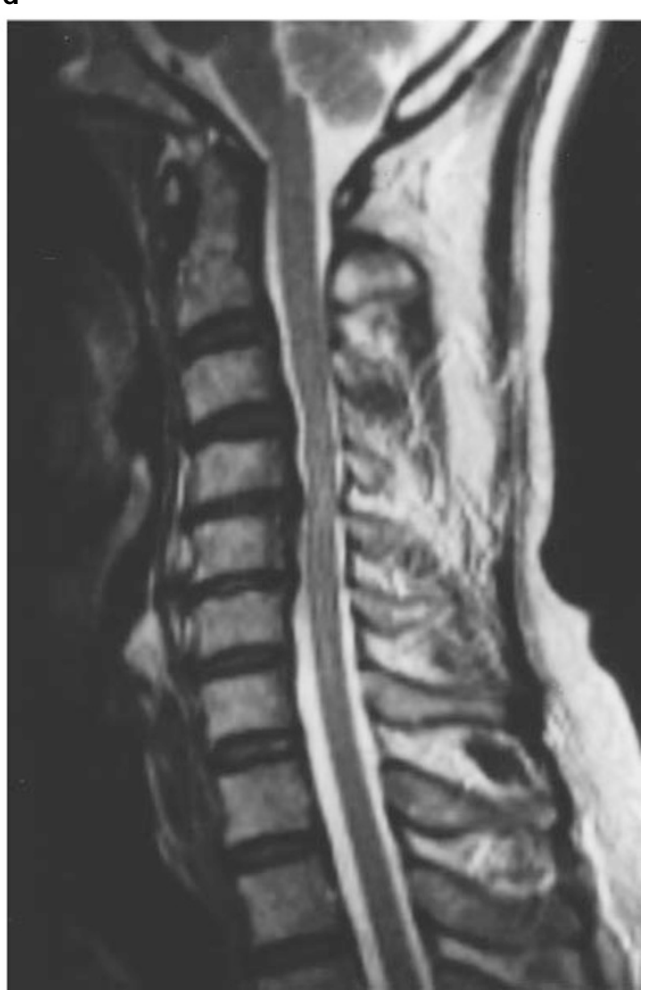

Figure 1 A 57-year-old man (Group 1) who suffered from Schneider-type impairment and was treated conservatively. His improvement by JOA and ASIA was $76 \%, 81 \%$ respectively. (a) Lateral roentgenogram showing cervical spondylosis. (b) Lateral myelogram showing partial block of the contrast medium at $\mathrm{C} 4 / 5$. (c) T2-weighted sagittal magnetic resonance image (MRI) of 2 days after injury shows the anterior and posterior compression of spinal cord at $\mathrm{C} 4 / 5$, and indicating intramedullary high intensity lesion. (d) MRI of 3 weeks after injury shows that the high intensity lesion decreases in size 
Table 5 Summary prognosis in Group 2 and 3 patients $(n=21)$

\begin{tabular}{lcccc}
\hline $\mathrm{AA}$ & $\mathrm{AB}$ & $\mathrm{AC}$ & $\mathrm{AD}$ & $\mathrm{AE}$ \\
0 & 0 & 0 & 0 & 0 \\
$\mathrm{BA}$ & $\mathrm{BB}$ & $\mathrm{BC}$ & $\mathrm{BD}$ & $\mathrm{BE}$ \\
0 & 1 & 0 & 0 & 0 \\
$\mathrm{CA}$ & $\mathrm{CB}$ & $\mathrm{CC}$ & $\mathrm{CD}$ & $\mathrm{CE}$ \\
0 & 0 & 2 & 4 & 1 \\
$\mathrm{DA}$ & $\mathrm{DB}$ & $\mathrm{DC}$ & $\mathrm{DD}$ & $\mathrm{DE}$ \\
0 & 0 & 0 & 5 & 8 \\
$\mathrm{EA}$ & $\mathrm{EB}$ & $\mathrm{EC}$ & $\mathrm{ED}$ & $\mathrm{EE}$ \\
0 & 0 & 0 & 0 & 0 \\
\hline
\end{tabular}

In each square of the grid are two letters of the alphabet of Frankel classification, the first related to the neurological lesion on the first examination and the second to the neurological lesion on last follow-up

showed cord compression by disc herniations, while the other six patients did not demonstrate cord compression. We found intra-meduallary lesions on three cases with MRI examinations. We demonstrated a case of Group 1 in Figure 1.

Surgically treated patients (Groups 2 and 3, $n=21$ ) included two patients with upper extremity impairment, 12 patients with Schneider-type impairment and seven patients with incomplete transverse syndrome. They showed score increases from $8.2 \pm 4.1$ to $11.6 \pm 4.7(P<0.0001)$ and from $78.0 \pm$ $25 . \overline{4}$ to $87.1 \pm 21.1 \quad(P<0.005)$ by JOA and ASIA respectively. Their improvement in JOA and ASIA score was $48.2 \pm 30.7 \%$ and $61.2 \pm 39.6 \%$, respectively. The $57 \%$ of Groups 2 and 3 had one grade improvement by the Frankel classification, while 5\% had two grades improvement (Table 5). There was no significant difference in the means of improvement in JOA and ASIA scores by the two surgical procedures, anterior inter-body fusion and laminoplasty. Group 3 patients $(n=7)$ improved more than those in Group $2(n=14)$. Group 2 improvements in JOA and ASIA score was $33.2 \pm 23.4 \%$ and $47.8 \pm 37.1 \%$ respectively, while improvement in Group 3 was $78.3 \pm 19.1 \%$ and $88.2 \pm 31.2 \%$ (Table 3). Patients with Schneider-type impairment $(n=12)$ had significantly better improvement than the patients with incomplete transverse impairment $(n=7)$. Schneider-type patients' improvement by JOA and ASIA score was $61.9 \pm 9.8 \%$ and $68.6 \pm$ $15.4 \%$ respectively, while improvement for the incomplete transverse impairment patients was $21.9 \pm 14.5 \%$ and $27.3 \pm 11.5 \%$. Until a operation Group 2 patients had improved by only $6.2 \pm 13.4 \%$ and $7.2 \pm 18.3 \%$ by JOA and ASIA scores respectively, while Group 3 patients had improved by only $8.5 \pm 6.1 \%$ and $9.1 \pm 11.3 \%$. The eight cases indicated intra-medullary lesion of MRI examination. The two cases, which belonged to incomplete transverse syndrome group, showed low intensity lesions on T1-weighted MRI.

\section{Discussion}

Thirty-three patients with spinal cord injury without radiographic evidence of trauma (SCIWORET) were studied. Patients with demonstrated persistent spinal cord deformity whose neurological recovery has reached a plateau became surgical candidates. Other patients received conservative treatment. Application of these criteria resulted in good clinical improvement for both forms of treatment. Patients operated on for single-level compression group (Group 3) had better improvement than those operated on for multi-level compression group (Group 2). It was suggested that the low score of Group 2 on the first examination might take part in those results.

Shingu et $a l^{12}$ have reported that the most frequent overall cause of spinal cord injury in Japan was traffic accidents, followed by falls from heights; The mean age at time of injury was 48.6 years. Younger patients tend to be subject to higher forces of injury. ${ }^{13}$ The present study revealed that relatively milder trauma predominates in older adults and results in SCIWORET. In this study, the most frequent cause of injury was falls at ground level, followed by traffic accidents and falls from heights. The mean age at time of injury was 55.6 years. For approximately $25 \%$ of reported spinal cord injury patients, alcohol consumption was a factor in injury. ${ }^{14}$ In this study, $15.2 \%$ of patients were under the influence of alcohol. Hyperextension injuries are the most common mechanism in central cord syndrome. ${ }^{15}$ The ligamentum flavum buckles inwardly against the posterior aspect of the spinal cord, while the bulging disc compresses the cord anteriorly. Schneider and Schemm concluded that a partial or relative insufficiency of the vertebral arterial supply to the cervical cord played a role in development of these lesions. $^{16}$ In extension injuries roentgenographic alignment varies, and there may be no signs of injury on roentgenograms except for pre-vertebral soft tissue swelling. 17

The syndrome of acute central spinal cord injury originally described by Schneider ${ }^{7}$ is characterized by greater motor impairment of the upper than the lower extremities, bladder dysfunction, and variable sensory loss below the level of the injury. In the present study, patients were classified as having upper extremity impairment, Schneider-type impairment, or incomplete transverse syndromes. ${ }^{8,9}$ We observed better neurologic improvement in the upper extremity and the Schneider-type groups than in incomplete transverse syndrome patients.

Controversy has continued as to whether conservative $^{3,7}$ or surgical ${ }^{18-21}$ treatment is better for central cord injury. Because of the considerable variation in SCIWORET, treatment should be decided according to degree of injury and improvement. We obtained good neurological recovery after operation, with significantly more improvement in single level anterior compression group (Group 3) than in a group of multi level lesions (Group 2). Timing of 
a

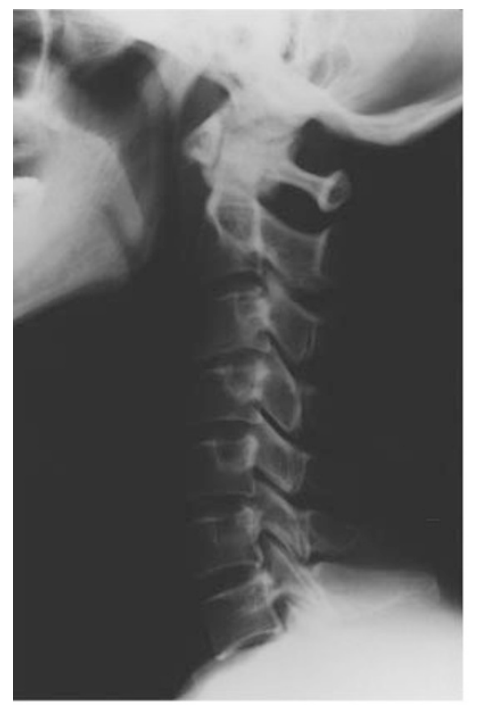

b

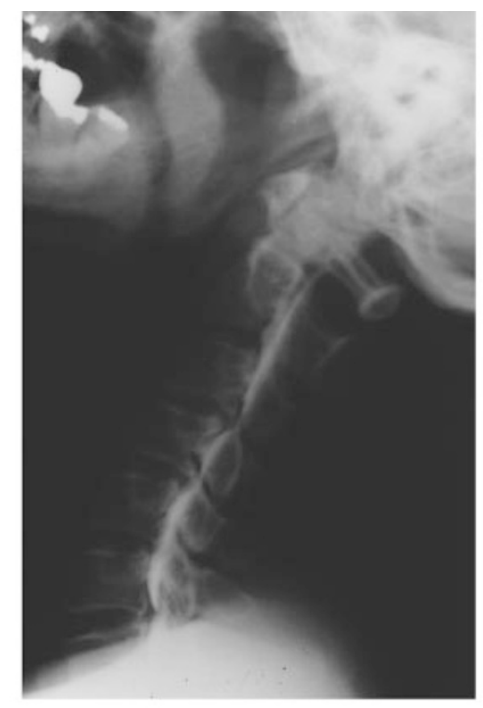

C

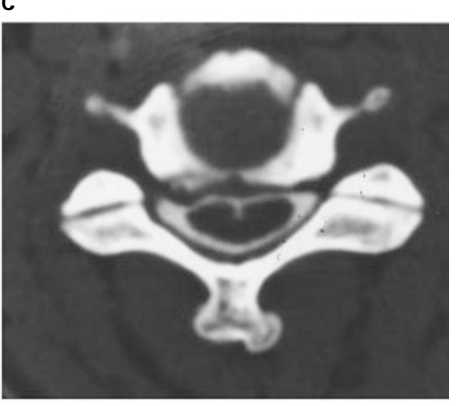

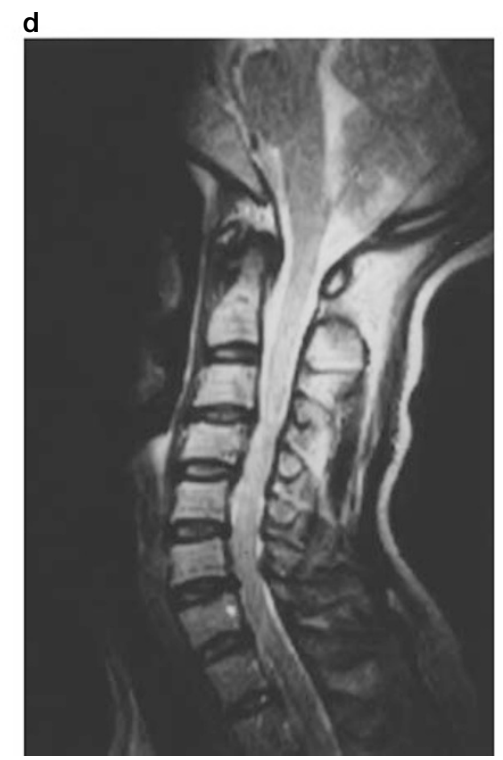

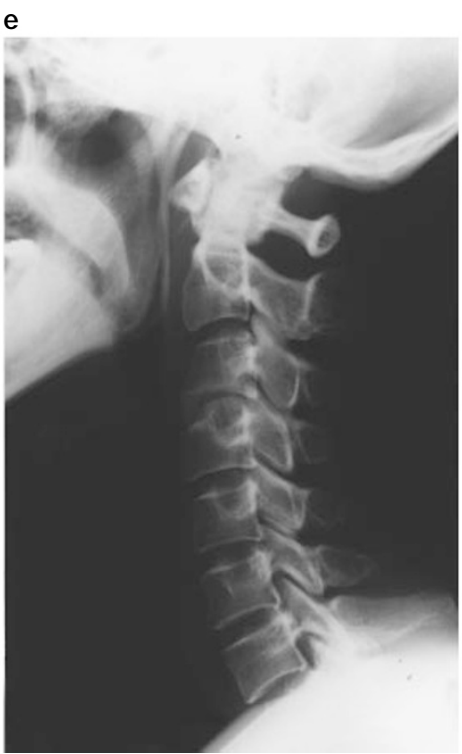

Figure 2 A 49-year-old woman (Group 3) who suffered from incomplete transverse injury and was treated by surgery. Her improvement by JOA and ASIA was $69 \%, 71 \%$ respectively. (a) Preoperative lateral roentgenogram showing mild angulation at C3/4. (b) Lateral myelogram showing localized constriction at C3/4 anteriorly. (c) Computed tomographic myelopathy of C3/4 showing anterior compression of dura. (d) T2-weighted sagittal MRI of 3 days after injury shows the anterior compression of spinal cord at C3/4. (e) Anterior inter-body fusion was performed using Robinson-Smith method at C3/4

surgery also has been the subject of much debate. Our average interval between injury and operation was $4.3 \pm 4.4$ months, representing delayed operation. Although some authors recommend acute surgical intervention, ${ }^{22}$ we obtained good results from delayed operation for central cord injury. Many studies have demonstrated that mechanical compression of the spinal cord could cause injury and that its continued presence could prevent improvement. Bohlman and
Anderson reported that anterior decompression, even when performed late after injury, could improve neurologic function in quadriplegia patients. ${ }^{23,24}$ Decompression can restore blood flow to the spinal cord and may result in further improvement. We believe that SCIWORET patients whose neurologic recovery has arrested and who have demonstrated compression of the spinal cord should have surgical treatment. 


\section{References}

1 Pang D, Wilberger JE. Spinal cord injury without radiographic abnormalities in children. J Neurosurg 1982; 57: 114-129.

2 Tator CH. Clinical manifestations of acute spinal cord injury. In: Benzel EC, Tator CH (ed). Contemporary Management of Spinal Cord Injury. American Association of Neurological Surgeons: Park Ridge Illinois, 1995, pp 15-26.

3 Bosch A, Stauffer S, Nickel VL. Incomplete traumatic quadriplegia: A ten year review. JAMA 1971; 216: 473 - 478 .

4 Frankel HL et al. The value of postural reduction in the initial management of closed injuries of the spine with paraplegia and tetraplegia. Paraplegia 1969; 7: 179-192.

5 Ditunno JF, Young W, Donovan WH, Creasey G. The international standards booklets for neurological and functional classification of spinal cord injury. Paraplegia 1994; 32: $70-80$.

6 Japanese Orthopaedic Association. Criteria on the evaluation of the treatment of cervical myelopathy. J Jpn Orthop Assoc 1976; 50: 18 - 20 (in Japanese).

7 Schneider RC. The syndrome of acute central cervical spinal cord injury with special reference to the mechanisms involved in hyperextension injuries of cervical spine. J Neurosurg 1954; 11: $546-577$.

8 Merriam WF, Taylor TKF, Ruff SJ, McPhail MJ. A reappraisal of acute traumatic central cord syndrome. J Bone Joint Surg 1986; 68-B: $708-713$

9 Usui H, Hirabayashi K. Acute central cervical spinal cord injury. Seikeigeka, 1981; 32: 1803 - 1812 (in Japanese).

10 Bracken MB. Treatment of acute spinal cord injury with methylprednisolone: results of a multicenter, randomized clinical trial. J Neurotrauma 1991; 8: S47-S52.

11 Bracken MB. Pharmacological treatment of acute spinal cord injury: current status and future projects. J Emerg Med 1993; 11: $43-48$.

12 Shingu H, Ikata T, Katoh S, Akatsu T. A nationwide epidemiological survey of spinal cord injuries in Japan from January 1990 to December 1992. Paraplegia 1995; 33: $183-188$.

13 Tator CH. Epidemiology and general characteristics of the spinal cord injury patient. In: Benzel EC, Tator $\mathrm{CH}$ (ed). Contemporary Management of Spinal Cord Injury. American Association of Neurological Surgeons: Park Ridge Illinois, 1995, pp 9-14.
14 Tator CH, Duncan EG, Edmonds VE. Changes in epidemiology of acute spinal cord injury from 1947 to 1981. Surg Neurol 1993; 40: $207-215$.

15 Marar BC. Hyperextension injuries of the cervical spine: The pathogenesis of damage to the spinal cord. J Bone Joint Surg 1974; 56-A: $1655-1662$.

16 Schneider RC, Schemm GW. Vertebral artery insuffinciency in acute and chronic spinal trauma with special reference to the syndrome of acute central cervical spinal cord injury. J Neurosurg 1961; 18: $348-360$.

17 Whitley JE, Forsyth HF. The classification of cervical spine injuries. Am J Roentgenol 1960; 83: 633-644.

18 Brodkey JS, Miller CF, Harmody RM. The syndrome of acute central cervical spinal cord injury revisited. Surg Neurol 1980; 14: $251-257$.

19 Fox JL, Wener L, Drennan DC. Central spinal cord injury: Magnetic resonance imaging confirmation and operative considerations. Neurosurg 1988; 22: $340-347$.

20 Maroon JC, Abla AA, Wilberger JI. Central cord syndrome. Clin Neurosurg 1991; 37: 612-621.

21 Roth EJ, Lawler MH, Yarkony GM. Traumatic central cord syndrome: Clinical features and functional outcomes. Arch Phys Med Rehabil 1990; 71: 18-23.

22 Sonntag VKH, Francis PM. Patient selection and timing of surgery. In: Benzel EC, Tator CH (eds). Contemporary Management of Spinal Cord Injury. American Association of Neurological Surgeons: Park Ridge Illinois, 1995, pp 97-107.

23 Bohlman HH, Anderson PA. Anterior decompression and arthrodesis of the cervical spine: Long-term motor improvement. Part 1 - Improvement in incomplete traumatic quadriparesis. J Bone Joint Surg 1992; 74-A: 671-682.

24 Anderson PA, Bohlman HH. Anterior decompression and arthrodesis of the cervical spine: Long-term motor improvement. Part II - Improvement in complete traumatic quadriplegia. J Bone Joint Surg 1992; 74-A: 683-692. 